American Journal of Pharmaceutical Education 2019; 83 (10) Article 7447.

\title{
RESEARCH
}

\section{Pharmacy Students' Lived Experiences of Academic Difficulty and Tinto's Theory of Student Departure}

\author{
Angie N. Choi, EdD, Geoffrey M. Curran, PhD, Earl J. Morris, BS, Ahmed M. Salem, BA, \\ Brent D. Curry, BS, Schwanda K. Flowers, PharmD \\ University of Arkansas for Medical Sciences, College of Pharmacy, Little Rock, Arizona \\ Submitted October 24, 2018; accepted May 20, 2019; published December 2019.
}

\begin{abstract}
Objective. To understand students' lived experiences of academic difficulty in pharmacy school in relation to Tinto's conceptual schema of student departure.

Methods. A descriptive, single case study design was chosen to explore academic difficulty in pharmacy school, and the unit of analysis (case) in this study was the experience of academic difficulty. Four students who had experienced academic difficulty in pharmacy school were recruited to participate in the study. Data sources included admissions applications, transcripts, emails to the lead researcher, and semi-structured interviews. Prior to analysis, the researchers created a coding dictionary to operationalize codes for textual analysis. Intercoder agreement was established at $97 \%$ agreement. Research validity was supported by triangulation of data, multiple researchers, and member checking. Results. Three of the four students were retained because of the synergistic reinforcement of academic and social integration based upon Tinto's schema. A fourth student was academically dismissed and departed the college, suggesting that too many social responsibilities in pharmacy college reduces time for academic integration, thereby diminishing the reciprocal potential between academic and social integration. Among the four students, seven main themes were identified: student background, goal of becoming a pharmacist, academic integration during pharmacy school, social integration during pharmacy school, retention and departure, roles and responsibilities during pharmacy school, and wellness. Conclusion. The results suggest that Tinto's theory of student departure is applicable to students' experiences of academic difficulty. These student stories suggest that early identification of student support needs may help pharmacy programs improve student retention.
\end{abstract}

Keywords: academic difficulty, Tinto's theory, student departure, student experiences in pharmacy school

\section{INTRODUCTION}

When students begin pharmacy school, they undergo significant transitions from undergraduate college, the workplace, and/or their home. Students all must meet prerequisite coursework requirements and be admitted through a selective process by admissions committees, yet some still underperform and struggle during the first year of pharmacy school and beyond. Even for students who are at the top of their class in their pre-pharmacy course work, transitioning to pharmacy school can be challenging. Students must suddenly adjust to a new rigor level and pace in their professional coursework, establish new peer and faculty relationships, and cope with high levels of stress, all while maintaining their family and work relationships and

Corresponding Author: Angie N. Choi, University of Arkansas for Medical Sciences, College of Pharmacy, 4301 West Markham St., Slot \#522, Little Rock, AR 72205. Tel: 501-686-8889. Email: anchoi@uams.edu. responsibilities outside of pharmacy school. ${ }^{1}$ During this abrupt transition, some students perform poorly. Students at our institution are monitored closely and support mechanisms, including study contracts, weekly time management logs, supplemental instruction, faculty office hours, test-taking skills development and peer tutoring at the university academic success center, and counseling services at the university wellness center, are provided. As a student progresses through pharmacy school, academic difficulty, left unaddressed, may have deleterious effects leading to the student's departure.

Although academic difficulty in pharmacy school has been studied through the quantitative lens of grade point average (GPA) and standardized test scores, to our knowledge, no studies have focused on the experience of academic difficulty in pharmacy school through a qualitative lens based upon students' lived experiences. ${ }^{2-10}$ A diversity of experiences shape our students' characteristics, abilities, and aspirations, and they bring these 
attributes with them as they interact within pharmacy school environments. Students cannot be viewed as blank slates when they enter higher education, and pharmacy schools cannot assume all students need the same support in order to graduate. ${ }^{11}$ Academic difficulty reflects something back to pharmacy schools beyond just poor academic performance and necessitates a holistic perspective on understanding why it unfolds in order to better support students. The objective of this study was to investigate pharmacy students' lived experiences of academic difficulty in relation to Tinto's theory of student departure to support students in difficulty and improve their retention.

Student retention has been widely studied for over five decades. ${ }^{12}$ Many researchers have developed theories regarding why some students leave college while others persist, and these theories have been studied across diverse student populations and institutional types, but student retention is still a significant problem in higher education. Tinto was the first student departure scholar to conceptualize a longitudinal schema that accounted for connections between individuals and their environments over time. ${ }^{12}$ He formulated his schema based upon two theories, Durkheim's suicide theory and cost/benefit analysis theory, for application with college students and settings. ${ }^{13}$ Tinto's schema is illustrated in Figure 1 and depicts that a student's goal commitment of attending college is influenced by family background, precollege schooling, and individual attributes. As students progress through college, they interact with an academic system that is comprised of their grade performance and intellectual development in their academics. Simultaneously, students also interact with the social system that consists of peer group interactions and faculty or staff interactions. Their academic experiences evolve into academic integration that reinforces their goal commitment (graduating); the more academically integrated students are, the more likely they will be able to graduate. Similarly, their social experiences develop into social integration that strengthens their institutional commitment to their college. The more socially integrated students feel in their college, the less likely they will be to leave. Both academic and social integration occur longitudinally and not as a single academic experience or social interaction. The extent to which students' goal commitments and institutional commitments are weak influences whether or not the goal of finishing college diminishes, ie, whether attrition occurs. Inversely, the extent to which these commitments are strong supports student retention.

When categorizing types of student departure, Tinto made distinctions between voluntary exit, in which case a student might transfer to another institution but still

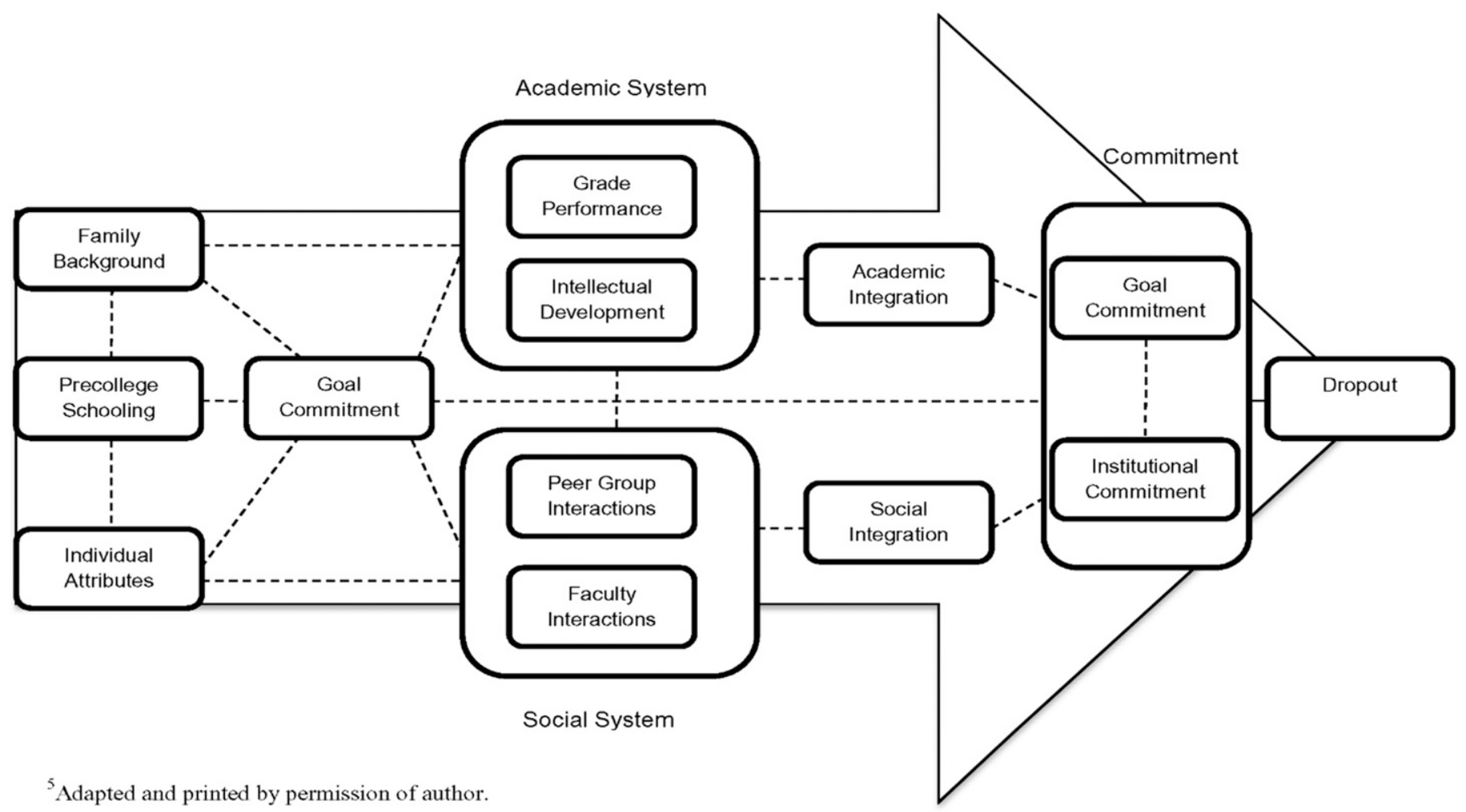

Figure 1. Tinto's Student Departure Schema 


\section{American Journal of Pharmaceutical Education 2019; 83 (10) Article 7447.}

graduate from college, and forced departure (dismissal), in which case a student would be less likely to graduate from college. Tinto's theory was originally conceived for college student departure, but research on student retention in professional programs supports similar departure factors that are included in Tinto's theory. ${ }^{14,15}$ Tinto's schema on student departure guided this study because students who experience academic difficulty are more likely to drop out and or be dismissed, and students' experience of academic difficulty occurs longitudinally. Another reason for using Tinto's theory was because he proposed that individuals' backgrounds shape their initial goal commitments to attend college as well as their academic and social interactions while there. ${ }^{13}$ In this study, we assessed the applicability of Tinto's theory to students' experiences of academic difficulty in pharmacy school.

\section{METHODS}

A descriptive case study design was chosen to capture how students experience academic difficulty in real world contexts. The researchers chose the case study design to explore the experience of academic difficulty, which was not understood beforehand. It also provided an open-ended method to approach the phenomenon of academic difficulty. The qualitative case study allows researchers to study complex phenomena as they naturally occur in context, which was crucial because of the nature of this study. ${ }^{16}$ A descriptive case study is used when describing an experience in a real life context or when trying to answer how or why questions, and the unit of analysis is the aspect that is being analyzed, which may be an event, individuals, groups, experiences or processes. ${ }^{17}$ The unit of analysis or case in this study was the experience of academic difficulty. The single case design included four units of analysis, which in this context were pharmacy students who had experienced academic difficulty. Academic difficulty was defined as a student experiencing any of the following: earning a cumulative GPA of 2.0 or lower out of 4.0 possible, failing a course, repeating a course in summer school, or repeating the P1 year (first year of a Doctor of Pharmacy degree program).

This study was conducted at the University of Arkansas for Medical Sciences College of Pharmacy and approved by the university's institutional review board. In the fall of 2017, prospective participants for this study were identified from among 120 students in the first-year pharmacy (P1) class of 2015-2016 based upon those who had experienced academic difficulty throughout that year. Students were first identified as having experienced academic difficulty by reviewing academic records for the fall 2017 semester. Grade point average (GPA), academic transcript, and summer school enrollment reports from the 2015-2016 academic year were downloaded from the student information system. A database of all students meeting any academic difficulty criteria was then created. Thirteen students were eligible to be included in the study, but four of these students either withdrew or were dismissed from the college, which left nine potential participants. After identifying the population of students, the researchers purposively selected four of the nine students and invited them to participate in the study during the fall semester of 2017. One participant had failed a course and retook it during summer school, two students had repeated the P1 year, and one student had a GPA below 2.0. The researchers chose four participants for the study because these students together were representative of all definitions of academic difficulty, they exhibited different degrees of academic and social integration, which allowed for a wider testing of Tinto's schema, and four was a feasible number to study.

One of the four participants was a student who was dismissed. Dismissed students were not initially considered for participation in the study because of the difficulties that recruiting them after they had left the program would have presented and because of the sensitive nature of the request. However, after an attempt to recruit a student who had transferred out of the college failed, the researchers invited a student who had been dismissed to participate because we believed the student would be willing to do so. Inclusion of the student helped researchers understand academic difficulty in relation to Tinto's theory of being highly socially integrated in pharmacy school but being dismissed nonetheless. This type of experience of academic difficulty would have been missing in the study otherwise. Ultimately, four participants were recruited for the study. Pseudonyms are used in this study to maintain anonymity.

To determine their interest in participating in the study, each student was sent a letter which described the purpose of the study, outlined what participation would entail, and included a confidentiality statement. The lead researcher then met with all participants individually to discuss participation in the study and to acquire informed consent. Initially, all four participants agreed to be in the study, but one student later withdrew prior to the interview phase of the study because of the sensitive nature of the interview. However, this student did consent to all other data (email to researcher, admissions application, academic transcript) except for the interview to be included in the study. No incentives were given to participants; however, participants were sent the findings of the research study.

Data collection began in October 2017 and was completed by February 2018. Data sources included 


\section{American Journal of Pharmaceutical Education 2019; 83 (10) Article 7447.}

admission application essays, special life circumstance essays, academic transcripts, and interviews. The first two data items were downloaded from the Pharmacy Centralized Application Service (PharmCAS). The admission essay prompted applicants to describe why they selected pharmacy as a career, what their career goals were, and how their personal, educational, and professional background would help them reach their goals. In the PharmCAS application, there is a special life circumstances text field where students may relate overcoming any type of adversity in their lives. Given the importance of student backgrounds, family relationships, formative pre-pharmacy school education, and individual goals, both the admission essay and special life circumstance text were expected to be rich sources of data to use in understanding the students' academic difficulty in relation to Tinto's theory.

Transcripts were acquired through student records. Semi-structured interviews were facilitated by an interview question guide that was informed by Tinto's schema. Interviews were conducted from January to February 2018 in person in a private faculty office with an experienced interviewer in qualitative methods. One interview was conducted by telephone because of the distance the student would have had to travel to participate in person. Interviews were audio-recorded using a dictation recorder and all audio files were deleted from the audio recorder after transfer of the audio files to the lead researcher. Interview files were manually transcribed by student researchers. For all participants, the researchers were able to stop collecting data after one interview. Because semi-structured interview questions were used and because of the narrative nature of the interview, conducting additional interviews would have been redundant. ${ }^{18}$ The participant's anonymity was protected by using codes for all student data including interview files. Participants were also informed that their anonymity would be maintained via pseudonyms for dissemination of results in scholarly journals.

To address trustworthiness and support research validity, we used triangulation of data, multiple researchers, and member checks. Pharmacy school applications, special life circumstance essays, transcripts, and interviews were used to triangulate data by providing multiple data sources for credibility. Four researchers analyzed the data for agreement, and then a fifth researcher later reviewed the study to confirm the findings. Research participants also reviewed researchers' analyses of their data for accurate representation of participants' intended meanings and also to reduce potential bias from researchers.

Prior to analyzing the data, four researchers met to create a coding dictionary. Creating a codebook allowed the research team to operationalize the codes for textual analysis. Initially, the codebook was developed by combining Tinto's concepts a priori with initial readings of transcripts and special life circumstance and admissions essays from PharmCAS applications. Each code was defined with agreement from the research team, and examples of each code were also discussed. After the codebook was developed, transcribed interviews were then imported into MAXQDA, version 12 (VERBI Software, Berlin, Germany). Coding was then conducted separately by three researchers to establish a baseline for intercoder agreement. The lead researcher used the intercoder agreement function in MAXQDA to evaluate the percentage of segment agreement, which was set at $90 \%$ correlation. In order to have agreement between coders in any segment of the interview, separate coders must use the same code for the same passages of text in a segment with at least $90 \%$ overlap. For example, if there are 100 characters in a passage of text, 90 of the same characters must overlap between coders to correlate to $90 \%$ agreement.

According to Miles and Huberman, $80 \%$ consistency in intercoder agreement is considered a good level of reliability for qualitative studies. ${ }^{19}$ To establish a baseline for coding consistency, three researchers initially coded the same participant's interview, which resulted in $97 \%$ agreement. After determining coding consistency, the coding team met four more times to discuss and code each interview. Investigators used the constant comparison method for greater reliability. An iterative process of coding, cross-checking codes between coders, discussion to establish consensus, and identifying new codes followed. During each meeting, the coding team crosschecked for reliability by comparing how each researcher coded each interview. The coding team resolved any discrepancies through consensus and manually revised any codes after further discussion on nuances of meaning or intention in each interview. Finally, codes were entered into MAXQDA by each coder separately, and intercoder agreement for all interviews was analyzed. Ultimately, all interviews ranged between $94 \%$ and $98 \%$ consistency in coding agreement.

\section{RESULTS}

After analyzing the codes in context, seven main themes were identified: student background (henceforth referred to as "background"); goal of becoming a pharmacist (henceforth referred to as "goal"); academic integration during pharmacy school (henceforth referred to as "academic integration"); social integration during pharmacy school (henceforth referred to as "social integration"); roles and responsibilities during pharmacy school (henceforth referred to as "responsibilities"); wellness; and retention and departure. Each student's story is discussed 


\section{American Journal of Pharmaceutical Education 2019; 83 (10) Article 7447.}

in turn in relation to these themes (themes have been underlined for emphasis).

At the time of admission to pharmacy school, our first participant, Jane, had a GPA of 3.25, a PCAT score in the 43rd percentile, and an interview score of 6.8 out of a possible 7 points. Jane had attended a four-year undergraduate university, majored in biology, and graduated with a bachelor's degree. She was a nontraditional student and had been out of college for almost 10 years while working as a pharmacy technician. Jane was a wife and mother of one young child. She experienced academic difficulty by failing one course during the P1 year and retook the course in summer school.

Jane's background influenced her interest in pharmacy because her mother was addicted to medication. "My mother has basically struggled my whole childhood with prescription medication. So I saw that growing up, and dealt with that and everything that comes with that, from in and out of rehabs to family therapy things, so did all that." Later, when Jane had her own family, they became the main motivator to reach her goal. "My family is definitely a big driver for [me]. . .And like having worked and been out of school and working for 10 years in between. I was living paycheck to paycheck, and I know what that life is like and I want better for myself and my family."

During her P1 year, Jane did not feel academically integrated. She experienced difficulty in making the academic transition. "When you get here and you fail a test or two in a row and it starts to mess with your head and you're like 'what's going on? I can't do this." However, she also described how her perspective changed over time regarding her performance. "I remember the first test we took. I was like, 'I wanna good GPA.' I [was] like, 'here we go,' and I got a $\mathrm{C}$ and I bawled, and now when I get a $\mathrm{C}$ I'm like, 'praise the Lord.' I'll take it and I will do a dance down the hall." Although she did not feel academically integrated, Jane did feel socially integrated. "So, my two really good friends that I kind of came here [with] and first year - they're older too and they have families and kids, too." Jane had social support, but she was unable to study with her friends because they needed to study at home because of their schedules. Unlike her friends, Jane could not study at home. "I have to stay on campus to study cuz if I go. . .home my son is 90 to nothing all the time."

The theme of responsibilities during pharmacy school indicated that participants had parental roles and work responsibilities in addition to their academic work. Although working in pharmacy college took away from study time, it also served as an academic support in Jane's case. She explained how the pharmacists at work modeled patient counseling and helped her to understand how to talk with patients to prepare for objective structured clinical examinations (OSCEs), which are performancebased tests that evaluate clinical skills. The theme of wellness in Jane's case revealed the constant stress she experienced. Because she had made an F in the P1 year, she was constantly under pressure throughout pharmacy school to not fail another course or she would be dismissed according to the college's scholastic rules. "At home, even when I'm not thinking about school, there's a cloud over my head and it makes me honestly get emotional about it because it's so stressful all the time. Every class and test we take I have this fear [of] 'what if I don't do well, what if I fail?'...And even today, like now there's this level of pressure that I feel like I have that $90 \%$ of our class doesn't have."

Our second participant, Jack, was admitted to pharmacy school with a 3.18 GPA, $78^{\text {th }}$ percentile on the Pharmacy College Admission Test (PCAT), and an interview score of 5. Jack attended a public four-year university, double-majored in anthropology and biology, and enrolled in pharmacy school after earning 123 undergraduate semester hours without completing a bachelor's degree. Jack was 20 years old at the time he applied to pharmacy school but was nevertheless considered a nontraditional student because of his socioeconomic status, first-generation attending college status, and single-parent status. ${ }^{20}$ Jack experienced academic difficulty by earning less than a 2.0 GPA during the first semester of the P1 year.

Jack's background was unstable because of "substance abuse problems of absent parent figures." The fifth child out of nine siblings, Jack was born to a "methamphetamine-addicted mother," and until the age of six, he lived with his father or other relatives. He was raised in a low-income area and tried to avoid the "cyclic drug abuse" that was common in his environment. Jack was adopted by his aunt and under the "nurturing care" of her family he attended a math and science-focused public high school which was ranked nationally in the top 25 . During this time, his father died from a "drunken fall." Later during college, a friend encouraged him to work at a pharmacy, where his goal of becoming a pharmacist blossomed. He described the rewarding nature of the profession. "Being around a lot of the elderly people and people south of the interstate - people that don't have a lot of money - helping them with their prescriptions and making them feel like they are taken care of. . .um, that felt really good."

In regard to academic integration in pharmacy school, Jack had a difficult time focusing on academics during the P1 year. He had a 2.0 GPA and worried about being dismissed. He explained that he was "being dumb 


\section{American Journal of Pharmaceutical Education 2019; 83 (10) Article 7447.}

and...still working between 20-30 hours a week in pharmacy school, which was a terrible idea." He performed much better during the second year (P2) of pharmacy school. "I made a 4.0 my second year and a 2.0 my first semester so I spent way too much time doing other things my $\mathrm{P} 1$ year and then all my time doing pharmacy my P2 year. So I think I realized as time passed where I need to put my motivation. And as we go on, the more material I learn, the more I feel like I have a better scope of practice, and it definitely makes you more confident. . .about practicing as a pharmacist."

The theme of social integration was particularly noticeable in Jack's experience in pharmacy college. His positive interactions with his peers and professors made a significant difference in his academic performance and confidence. "So they [study group] helped me figure out what was important and then helped me understand some of the key concepts of connecting the dots of metabolism and the body processes. Like I was trying to study each thing in its own subset...so they helped me understand what was important in the material." He also described his office visits with faculty as "transformational," and collegial rather than as professor and student. "It's one of the more difficult classes that everyone complains about, but as we started going to Dr. Y, I think he became less scary, and he helped a lot so that transformed [his classes] for me... and then Dr. X...Having conversations with [Dr. X] about the class and the material, same thing, transformed my whole outlook for the class."

Regarding the theme of responsibilities, Jack related that he was more concerned about his child and work responsibilities during the $\mathrm{P} 1$ year instead of being focused on school. His role as a parent and working 20-30 part-time hours a week redirected his attention from academics. Jack explained that hardly being able to see his child, who lived three hours way with his ex-wife, also made the first year transition difficult. This combination of parental concern and stress about poor academic performance led to a significant decline in Jack's overall wellness. He described his condition during that time: "I was pretty anxious, or I was like, the anxiety or the stress from doing so bad made me anxious about even going to class. Like I was like, 'it doesn't matter, I'm going to do bad anyway'... I was probably drinking like every day in the afternoon or at night." He also mentioned that his physicians had prescribed medication to help him focus his attention, and he felt that it "helped a lot for sure." Even with these challenges, Jack never considered dropping out. The theme of retention and departure was present in Jack's narrative in a positive manner. He explained that he felt connected in pharmacy school due to his peer group, "I feel like it's home. . .my friend group, one of the people in it has a kid, and everyone is really cool and relaxed, and it's like a family."

Mary, the third participant, was admitted to pharmacy college with a $2.91 \mathrm{GPA}, 70^{\text {th }}$ percentile on the PCAT, and a 6.5 interview score. She attended a public land-grant, research university for her bachelor's degree with a major in chemical engineering and attended an online institution for her master's degree in accounting. Mary experienced academic difficulty and had to repeat the P1 year. Mary's background was that she was an underrepresented minority, nonresident student from a bordering state. Mary, who was 39 years old at the time of application, was a nontraditional student with four children, ages ranging from elementary to high school. Mary was born in a foreign country and had been living in her US residence for 13 years at the time of application.

One of the reasons for Mary's goal of becoming a pharmacist stemmed from her experience owning a medical supply business with her husband. She explained that she wanted to provide services to underserved communities. "One of the other reasons I also got into pharmacy, where we had our business [was] no one else wanted to put a business in. . It was a black neighborhood and mostly Medicaid patients. The impression I got was that no one cared. So I told myself, well those people need a pharmacist too." After experiencing academic difficulty during the P1 year, Mary was motivated to reach her goal because of her student loan debt. "Now, I've gotten to the situation that I had to come to a realization that after that first year I had to continue this because I have student loans of $\$ 45,000 /$ year, so I had to decide, 'Are you going to continue this or are you not?"'

Regarding the theme of academic integration, Mary described how a lack of confidence affected her performance even though she had tried different study approaches. "I second guess myself. Just the preparation I guess. I do, I spend a lot of time studying and I've tried different studying habits, but I guess I have to know it so well that that if I'm asked a question, but when I'm not so sure, I almost always choose the wrong one. I change answers often, I've tried, I've talked to different professors, I've tried different tactics - not changing answers, being confident, and I think that's part of the problem." Although Mary was socially integrated into different study groups, she was still frustrated that it did not seem to translate into better results on her examinations. She expressed her frustration in being unable to reconcile the greater knowledge she thought she had compared to her peers when studying in groups while earning lower examination results. "I've studied with different people, I've studied with different groups and I've studied with different students. I get along with most people and then 


\section{American Journal of Pharmaceutical Education 2019; 83 (10) Article 7447.}

one thing I've noticed is...it seemed that I knew the material a little bit better than they did, but when we would take the test, they would do a lot better than I do. And they've tried to help, tried to figure out what, what is it...They say, 'You're getting it,' but my scores don't show that."

Although Mary was socially integrated with her peer group, she did not approach her professors for help. "It was kinda hard for me to go to a professor that you're failing their class. For me it was there are people that are good at it but I'm not. Because the impression is that you're not studying or not applying yourself. And then it's hard to explain that you're doing a lot but it's just not materializing into good grades, so I tended to avoid teachers, especially the first year."

Mary's responsibilities beyond her studies included being a mother to four children and also working parttime at a specialty pharmacy in her P2 year. During the P1 year, Mary's husband was often away travelling for work, and although a relative came to live with her to help with the children, Mary was the primary parental figure in the household. During the P2 year, she worked in an outpatient pharmacy with a specialty pharmacy group where she mostly worked with patients over the phone getting prior authorizations and talking to insurance companies. She explained the positive impact of her work in increasing her confidence in her knowledge. "What I like about this [specialty] setting, for me, because I'm not good at my drugs. . I take my time because I don't like making mistakes. Being in a specialized environment, I learn [medications] well, and I do much better than I did when I worked in a community setting."

The theme of wellness presented in Mary's experience as anxiety and panic attacks. "I do have problems with recall and I have problems with anxiety. I've already gone to the student wellness center and Dr. [Z] recommended a beta-blocker for me for anxiety because I did have some panic attacks. . . and also because I'm behind, I have the anxiety that I really can't do poorly but I end up doing poorly." Mary sought help for her mental health issues and persisted despite her academic difficulty and anxiety. In regard to the theme of retention and departure, she never thought of quitting pharmacy school and transferring to another one. She focused on the professionals she saw working in the field, had confidence in the program, took responsibility for her performance, and continued to work toward her goal despite the challenges she experienced. "Most of the pharmacists around here are students from here and you could tell they're doing a good job, so [it] means the school is a good one. I don't have any problems with the curriculum or anything, it's just I need to get my part of it done. And there are a lot of successful students, the NAPLEX scores show that, so I know it's a good program."

Mike, the fourth participant, was admitted to pharmacy school with 156 semester credit hours, a 2.92 GPA, a $52^{\text {nd }}$ percentile on the PCAT with a biology sub-score in the $84^{\text {th }}$ percentile, and a perfect score of 7 on his admissions interview. Mike did not have a bachelor's degree and attended a two-year college. He was a nonresident, first-generation, nontraditional student who was 33 at the time of application. Mike experienced academic difficulty and repeated the P1 year. He was dismissed from pharmacy school after the first semester of the repeated year after failing another course.

The background influences on Mike's pathway to pharmacy college included his love for science, his natural talent in biology and chemistry, and his parents' addiction to prescription medicine. Mike related how as a young child, he studied "snakes and insects in [the] backyard." Mike's innate curiosity in biology occurred in tandem with instability in his household. He described the "pandemonium" at home. "During the course of my parent's recovery, my parents dragged their children through a whirlwind of chaos." Mike's goal of becoming a pharmacist was shaped by his parents' difficulties. "My parents' struggles partook in my efforts in achieving this goal. They never went to college and because of that I witnessed, first hand, the financial strains my parents faced daily in raising four children. Though much of my parent's recovery was out of my control, what were in my control were my academic achievements. I used my schooling as an outlet...to enhance my knowledge, so that one day I would be able to educate and help others through challenging medical concerns." He was also motivated to his goal after shadowing a pharmacist in a clinical setting. This experience had an "enormous influencing impact" on him. "I knew after my job shadowing experience that I was going to pursue a career in pharmacy...Witnessing the impact of drug therapy and the therapeutic outcomes of...patients solidified my calling to improve the health of people in my community."

Other than having experienced academic difficulty and repeating the P1 year, not much is known about Mike's academic integration due to his withdrawal from the interview; however, Mike was socially integrated in pharmacy school to a high degree. A skilled communicator and caring individual, Mike was actively engaged in high-level leadership roles in his P1 cohort and consistently interacted with his peers and faculty in this role. Although he was ultimately dismissed from pharmacy school, he remained motivated to his goal as evidenced by the theme of retention and departure in his story. "My 


\section{American Journal of Pharmaceutical Education 2019; 83 (10) Article 7447.}

passion is still there and I'm not giving up. I plan to reapply to an out-of-state program this fall because I know my heart is in this profession." Mike remained serviceoriented and "helping others" continued to be a significant motivator to his goal.

\section{DISCUSSION}

The themes in each student's story can be applied to Tinto's theory of student departure to expand our understanding of the experience of academic difficulty. In Jane's case, the theme of background illustrated how her pre-pharmacy school education, childhood home environment, work experience, and desire for a better life influenced her goal commitment to become a pharmacist. Jane was exposed to her parents' prescription drug addiction in her childhood home and the vicissitudes of recovery. As an adult, Jane wanted a better life for her own family and was tired of low paid positions without holidays off. The theme of academic integration revealed that Jane did not interact much with her professors during the P1 year when experiencing academic difficulty. Being out of college and not having taken basic science courses for several years prior to pharmacy school may also have negatively impacted her academic experience. Although her academic integration was poor, the theme of social integration was evident. She felt connected to her class as a whole and had two good friends who had enrolled in pharmacy school the same year. Jane also had a good support group of nontraditional students with families. One of the most significant influences in Jane's academic remediation came about through her social interactions. Jane had gone to the university academic support center for peer tutoring, but the program paired a more senior student with her, and their sessions were not so fruitful because the peer tutor had to review notes from a prior year. Instead, Jane, through her own initiative, reached out to a high-performing classmate in the same cohort who was not a paid peer tutor but who was highly effective in helping Jane improve her grades. Jane's social support network made an important difference in her progress toward her goal. As Jane progressed through pharmacy school, her family's welfare continued to be the strongest motivator toward her goal in addition to the significant debt from pharmacy school that she would not be able to repay without a professional salary.

The theme of background in Jack's case revealed how formative his childhood home life and prepharmacy school education was in shaping his goal. His unstable family life could have derailed his future, but his prestigious math and science-focused high school became a positive environment where his intellect and confidence could develop. His aunt and her family provided a stable, nurturing home life where service to others was valued, and Jack's experience working with the elderly and poor in a pharmacy during college helped him to identify his career goal of pharmacy. The theme of academic integration during the P1 year indicated poor academic commitment. As Jack explained, he was not attending classes and working too much. His time and energy were not focused on pharmacy school. The theme of social integration also indicated poor engagement during the P1 year. As he progressed to the second year of pharmacy school however, things changed. Jack's social integration increased because he found a peer study group who helped him integrate the material. As Jack reported, he began spending a large amount of time with them. His social interactions with his professors also increased. He attended faculty office hours regularly, and the collegial conversations he had with them completely changed the way he viewed himself. He felt affirmed by the way they accepted him and discussed the material like colleagues. According to Jack, he went from hardly spending any time to spending all his time on pharmacy school, and commensurately, his GPA went from a 2.0 in the first term to a 4.0 in second year. Jack's case is a dramatic example of the positive impact of social integration on a student's academic experience, and how the two systems in Tinto's theory, academic and social, synergistically reinforce each other.

Tinto's theory explains that students' backgrounds influence their goal commitments, which is evident in Mary's aspirations to a career in pharmacy. In Mary's case, her family background motivated her to pursue a career in pharmacy. She and her husband had a medical supply store, but needed more income, which prompted them to consider further education and a career change. Mary held a baccalaureate in chemical engineering, but she had been out of college for eight years, and continuing on in the field for her career seemed unmanageable as a mother with four children. Thus, Mary decided on pharmacy as a career to support her family and maintain work/life balance. Although Mary had been out of college for several years, she took prerequisite pharmacy coursework for two years prior to applying to pharmacy college.

The theme of academic integration indicated that time management and self-perception were issues. Mary reported that she perceived herself as a slower learner compared to her classmates, but at the same time, she also had greater responsibilities than most of her peers outside of the classroom. She mentioned that she doubted her abilities and was often confused as to why her studying did not translate into performance on examinations. In Tinto's theory, intellectual development is a part of the academic system, and pertains to how students view their 


\section{American Journal of Pharmaceutical Education 2019; 83 (10) Article 7447.}

intellectual abilities to think critically, be stimulated by coursework, and integrate into the intellectual norms of their academic environments. ${ }^{13}$ As Mary performed poorly on her examinations, she explained that her confidence eroded. In regard to the theme of social integration in pharmacy school, Mary did study with peers occasionally, but she did not interact with her professors in the courses where she was not performing well. She did not want them to think she was not trying, and chose not to seek help from them directly. During her second attempt of the P1 year, Mary, who had more experience the second time, joined a study group with high achieving students and pulled herself out of academic jeopardy (cumulative GPA of 2.2 or lower). She also described that she started seeing a campus therapist to address her anxiety which increased her social integration. Additionally, she began working at an outpatient pharmacy which helped her improve her knowledge of medications and develop her confidence. During her second attempt of the P1 year, Mary's social and academic integration was greater and more concordant, which helped her to progress academically.

The theme of background was significant in Mike's case. His aspiration to pursue a career in pharmacy began with his innate curiosity in science. Like Jane, Mike was exposed to prescription medications in the home through his parents' addiction and recovery, which also influenced his goal. Additionally, he experienced financial instability as a child and wanted better for himself. Like Jack, Mike used his schooling as an outlet from the chaos of his home environment and viewed education as a pathway to a better life. Tinto theorizes that the more socially integrated the student is in the institution, the greater the likelihood of institutional commitment, which results in retaining the student. Despite this proposition, a tipping point exists where too much social integration could adversely impact student success. Although Mike was a student leader and interacted heavily with peers and faculty, he experienced academic difficulty because he was spending much of his time on leadership responsibilities. During his second attempt at the P1 year, he did not participate in leadership roles but eventually made another $\mathrm{F}$ which resulted in dismissal from pharmacy school. Mike withdrew his consent for an interview so the researchers were unable to provide more information on his experience of academic difficulty. Tinto's theory explains that students who are dismissed are less likely to continue toward their goal compared to those who voluntarily withdraw. At the time of this study however, Mike had applied to another pharmacy college instead of abandoning his goal of becoming a pharmacist. Perhaps the high debt amount and high stakes nature of professional school compel students to continue toward their goals.

One commonality for all participants for the theme of background was that all were nontraditional students. The definition of the nontraditional student population has changed throughout decades of research from being based on age to a combination of background variables such as employment status while enrolled, first-generation college attendance, and low socioeconomic status. ${ }^{20}$ Later, potential attrition risk factors also came to define nontraditional students such as being a single parent, having dependents while enrolled, attending part-time or delayed enrollment. ${ }^{20}$ At the time of applying to pharmacy college, Jack was twenty years old, and the rest were in their thirties. Three participants were parents before attending pharmacy college. The literature on academic difficulty also indicated that family commitments outside of health professions programs were associated with academic failure or early signs of difficulty. ${ }^{21,22}$ The students in our analysis also experienced difficulty in managing their time, schedules, and behaviors because of family responsibilities. However, to equate family responsibilities with academic failure would be one-sided, as providing for a family presented as a strong motivator toward their goal commitment of becoming a pharmacist in our study.

Examination of the applicability of Tinto's theory to students' experience of academic difficulty in pharmacy school indicated that social and academic integration do not appear to be independent of each other. As our students became more academically integrated in course work, study groups, internships, etc, they found themselves in a situation where academic integration shifted to social integration. What began as a common academic goal wound up as strong relationships with peers and future colleagues. When students develop these connections they have improved success in the classroom because of a culture of trust, inclusion and acceptance. ${ }^{23}$

Tinto's theory provides an applicable framework for retention of pharmacy students who experience academic difficulty. Programs should consider students' experiences and individual backgrounds in addition to academic variables when examining academic difficulty in the Doctor of Pharmacy (PharmD) curriculum. Often the lived experiences of students are overlooked or dismissed as we consider key indicators for early identification of student difficulty. Although the literature pertains to Tinto's theory in the undergraduate arena, this analysis suggests how Tinto's theory impacts students' success in a professional program. ${ }^{24}$ Examining student backgrounds and recognizing the varying support needed for students to be successful is critical. As students enter professional programs, their goal commitment is high, 


\section{American Journal of Pharmaceutical Education 2019; 83 (10) Article 7447.}

and the idea that the student experience would diminish this commitment, or that students' institutional commitment declines because of lived experiences and the level of support from the institution, is concerning. The longitudinal analysis of these student stories demonstrates how experiences may change over the course of the professional program. Early identification of a student's lack of academic and social integration appears key to student retention and success. This analysis suggests that intentional mentoring, facilitated study groups, selective peer tutoring, and increased positive faculty interaction may improve goal and institutional commitments. Addressing the idea of not fitting into intellectual norms in the academic environment would also be helpful for underperforming students who doubt their intellectual abilities when comparing themselves to their peers. In addition, the impact student wellness plays on success in the curriculum is a critical component of goal achievement. Timely referral to university student services by faculty and administration in such cases may have a positive impact on student retention and success.

The investigators acknowledged their potential biases toward the research project and bracketed their preconceived thoughts at the outset of the study. Bracketing is a process of identifying and disclosing prior beliefs and biases that may predispose researchers to certain thoughts in the research process, thereby supporting the rigor of research studies. ${ }^{25}$ Two of the lead investigators were student affairs professionals, and have advised students on academic and behavioral issues over the span of a decade combined. Additionally, one researcher had published a paper on academic difficulty, and another investigator had been influenced previously by Tinto's conceptual schema.

This study was limited by the absence of all types of departure experience according to Tinto's theory in the representation of student cases. Although the researchers attempted to recruit a former student who voluntarily withdrew from the college because of social rather than academic reasons, they were unsuccessful in their attempts. Another limitation of this study was the generalizability of results to other colleges of pharmacy whose student populations differ. This study investigated a small sample of students at a single pharmacy school. Further research with large populations and other health professions would be helpful in understanding the experience of academic difficulty in professional colleges.

\section{CONCLUSION}

Although academic difficulty has been studied in the health professions, students' voices on their experience of academic difficulty in pharmacy school are absent. The lived experiences in these student stories suggest that early identification of diverse backgrounds may help pharmacy programs improve student retention and success by recognizing the importance of social and academic integration as delineated in Tinto's conceptual schema. Further analysis of additional student experiences is needed to fully realize the complexity of student success in professional programs. The evaluation of admission application essays and special life circumstance essays for student support is recommended. This early identification may help students who otherwise may spend their first year in difficulty without engaging in timely help-seeking behaviors.

\section{REFERENCES}

1. Marshall LL, Allison A, Nykamp D, Lanke S. Perceived stress and quality of life among doctor of pharmacy students. Am J Pharm Educ. 2008;72(6):Article 137.

2. Alston GL, Battise DM, Neville MW. A 10-year study of the academic progress of students identified as low performers after their first semester of pharmacy school. Am J Pharm Educ. 2016;80(7):Article 118.

3. Schlesselman LS, Coleman CI. Predictors of poor student performance at a single Accreditation Council for Pharmacy Education-accredited school of pharmacy. Curr Pharm Teach Learn. 2011;(3):101-105.

4. Houglum JE, Aparasu RR, Delfinis TM. Predictors of academic success and failure in a pharmacy professional program. Am J Pharm Educ. 2005;69(3):Article 43.

5. Clavier C. Academic Performance of First-Year Students at a College of Pharmacy in East Tennessee: Models for Prediction [dissertation]. Johnson City: East Tennessee State University; 2013.

6. Kuncel NR, Credé M, Thomas LL, Klieger DM, Seiler SN, Woo SE. A meta-analysis of the validity of the Pharmacy College Admission Test (PCAT) and grade predictors of pharmacy student performance. Am J Pharm Educ. 2005;69(3):Article 51.

7. Hardigan PC, Lai LL, Arneson D, Robeson A. Significance of academic merit, test scores, interviews and the admissions process: a case study. Am J Pharm Educ. 2001;65(1):40-44.

8. Julian ER. Validity of the Medical College Admission Test for predicting medical school performance. Acad Med.

2005;80(10):910-917.

9. Lancia L, Petrucci C, Giorgi F, Dante A, Cifone MG. Academic success or failure in nursing students: results of a retrospective observational study. Nurse Educ Today. 2013;33(12):1501-1505. 10. Hansen DJ, Mort JR, Brandenburger T, Lempola A. Relationship of prepharmacy repeat course history to students' early academic difficulty in a pharmacy curriculum. Am J Pharm Educ.

2015;79(10):Article 154.

11. Kuh GD, Kinzie J, Buckley JA, Bridges BK, Hayek JC. Piecing Together the Student Success Puzzle. https://leseprobe.buch.de/ images-adb/55/7f/557f215a-68ad-475a-8e3f-2cda5ca61f5c.pdf. Association of Higher ducation Report. Published 2007. Accessed December 16, 2019.

12. Tinto V. Research and practice of student retention: What next? $J$ Coll Student Retent. 2007;8(1):1-19. 


\section{American Journal of Pharmaceutical Education 2019; 83 (10) Article 7447.}

13. Tinto V, Cullen J. Dropout in Higher Education: A Review and Theoretical Synthesis of Recent Research. https://files.eric.ed.gov/ fulltext/ED078802.pdf. Office of Education (DHEW). Published 1973. Accessed December 16, 2019.

14. Shelton EN. Faculty support and student retention. J Nurs Educ. 2003;42(2):68-76

15. Yates J. When did they leave, and why? a retrospective case study of attrition on the Nottingham undergraduate medical course. BMC Med Educ. 2012;12(1):1-7.

16. Yin RK. Case Study Research: Design and Methods. 3rd edition. Thousand Oaks, CA: Sage; 2003.

17. Baxter P, Jack S. The qualitative report qualitative case study methodology: study design and implementation for novice researchers. Qual Rep. 2008;13(4):544-559.

18. Anderson C. Presenting and evaluating qualitative research. $A m J$ Pharm Educ. 2010;74(8):Article 141

19. Miles M, Huberman A. Qualitative Data Analysis: A Sourcebook of New Methods. Thousand Oaks, CA: Sage; 1994.
20. Gilardi S, Guglielmetti C. University life of non-traditional students: engagement styles and impact on attrition. J Higher Educ. 2011;82(1):33-53.

21. Dante A, Valoppi G, Saiani L, Palese A. Factors associated with nursing students' academic success or failure: a retrospective Italian multicenter study. Nurse Educ Today. 2011;31(1):59-64.

22. Benda E. The relationship among variables in Tinto's conceptual model and attrition of bachelor's degree nursing students. $J$ Prof Nurs. 1991;7(1):16-24.

23. Bean J, Eaton S. The psychology underlying successful retention practices. J College Student Retent. 2002;3(1):73-89.

24. Tinto V. From theory to action: exploring the institutional conditions for student retention. In: Smart J, ed. Higher Education: Handbook of Theory and Research. Chicago, IL: University of Chicago; 2010:51-89.

25. Tufford L, Newman P. Bracketing in qualitative research. Qual Soc Work. 2012;11(1):80-96. 